\title{
PIE at ORNL \\ Post Irradiation Examination Capabilities for Structural and Non-Fuel Materials at Oak Ridge National Laboratory
}

\author{
Nuclear Materials Science and Technology Group \\ Materials Science and Technology Division \\ Oak Ridge National Laboratory \\ Oak Ridge, Tennessee 37831
}

February 2013

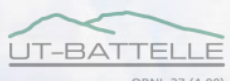

" OAK

RIDGE 


\section{DOCUMENT AVAILABILITY}

Reports produced after January 1, 1996, are generally available free via the U.S. Department of Energy (DOE) Information Bridge.

Web site http://www.osti.gov/bridge

Reports produced before January 1, 1996, may be purchased by members of the public from the following source.

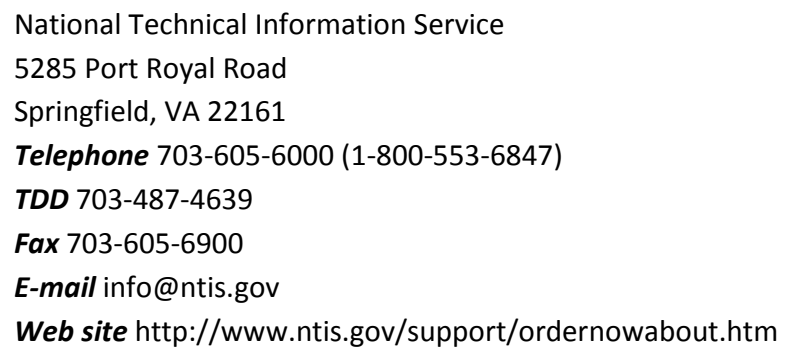

Reports are available to DOE employees, DOE contractors, Energy Technology Data Exchange (ETDE) representatives, and International Nuclear Information System (INIS) representatives from the following source.

Office of Scientific and Technical Information

P.O. Box 62

Oak Ridge, TN 37831

Telephone 865-576-8401

Fax 865-576-5728

E-mail reports@osti.gov

Web site http://www.osti.gov/contact.html

This report was prepared as an account of work sponsored by an agency of the United States Government. Neither the United States Government nor any agency thereof, nor any of their employees, makes any warranty, express or implied, or assumes any legal liability or responsibility for the accuracy, completeness, or usefulness of any information, apparatus, product, or process disclosed, or represents that its use would not infringe privately owned rights. Reference herein to any specific commercial product, process, or service by trade name, trademark, manufacturer, or otherwise, does not necessarily constitute or imply its endorsement, recommendation, or favoring by the United States Government or any agency thereof. The views and opinions of authors expressed herein do not necessarily state or reflect those of the United States Government or any agency thereof. 


\section{Post Irradiation Examination Capabilities for Structural and Non-Fuel Materials at Oak Ridge National Laboratory}

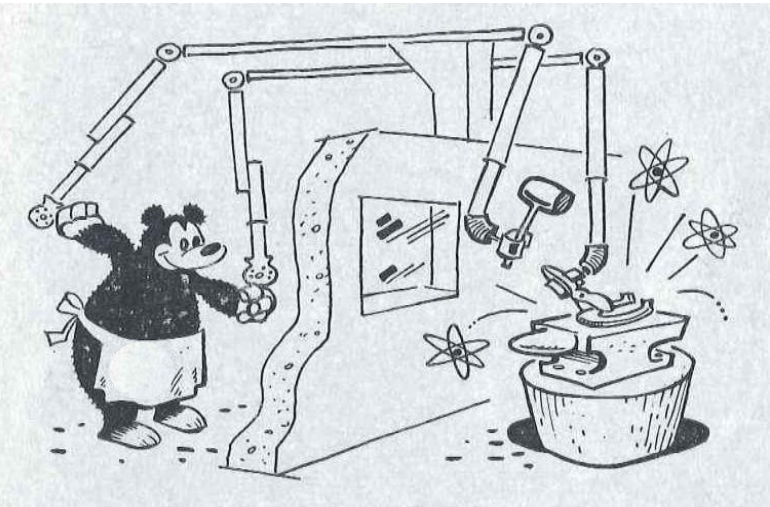

The Materials Science and Technology Division of Oak Ridge National Laboratory conducts fundamental and applied materials research for basic energy sciences programs and a variety of energy technologies. In the Nuclear Materials Science and Technology Group, we advance the materials science and technology base by conducting forefront research and development for a broad spectrum of nuclear power and fundamental science programs.

Our core competencies include:

- Radiation effects in metals, ceramics, polymers, composites and graphite

- Microstructure/property relationships

- Irradiated fuels examination

- Multiscale modeling of radiation effects in materials

- Fracture mechanics

- Radiation embrittlement mechanisms

- Physical metallurgy of structural alloys

- Mechanical properties of irradiated materials

To support these missions, we conduct research in laboratories throughout the Division and the Laboratory, including the Irradiated Materials Examination and Testing Laboratory (IMET), the Low Activation Materials Development and Analysis Laboratory (LAMDA), the Shared Research Equipment User Facility (ShaRE), and the High Temperature Materials Laboratory (HTML). MST division research staff also have strong interactions with the Center for Nanophase Materials Sciences (CNMS), the Center for Advanced Thin-Film Solar Cells (optical testing) Laboratory, and the neutron scattering facilities located at the High Flux Isotopes Reactor (HFIR) Center for Neutron Scattering and the Spallation Neutron Source (SNS).

OAK RIDGE NATIONAL LABORATORY

Oak Ridge, Tennessee 37830

Managed by

UT BATTELLE, LLC

for the

U.S. DEPARTMENT OF ENERGY

under contract DE-AC05-00OR22725 


\section{Irradiated Materials Examination and Testing Laboratory}

The Irradiated Materials Examination and Testing (IMET) hot cell facility is a Class III nuclear facility located in Building 3025E at Oak Ridge National Laboratory. These hot cells are the primary mechanical testing and examination facility at ORNL for highly irradiated structural alloys and ceramics. The six interconnected steel-lined hot cells contain 320 square feet of work space and are maintained as a low alpha contamination facility to facilitate transfer of specimens to other radiological laboratories after testing or sorting. An additional 600 square feet of work space for test equipment control systems and R\&D staff work stations is located in a contamination-free area in front of the hot cells. Functions that can be performed include tensile testing, laser profilometry, creep testing, Charpy impact and fracture toughness testing, fatigue testing, capsule disassembly, microscopic examination, grinding, polishing, welding, shearing, machining, sawing, photography, and video examination. The building has a convenient loading area for receiving and shipping carriers. A radioactive specimen preparation area is located adjacent to the hot cells and consists of three shielded glove boxes and a chemical hood with HEPA ventilation and connections to the ORNL low-level liquid waste system. This specimen preparation facility is used for preparation of transmission electron microscopy specimens and other specialized activities.

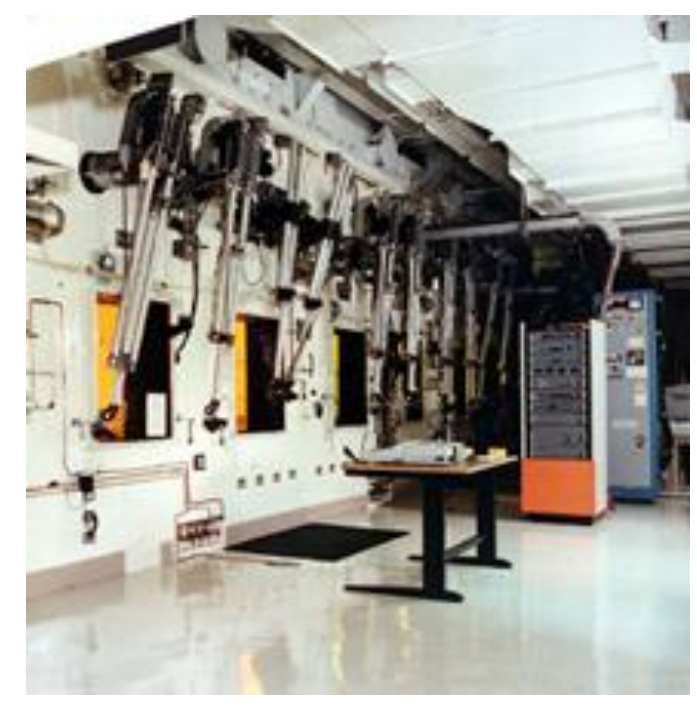

IMET has six interconnected hot cells

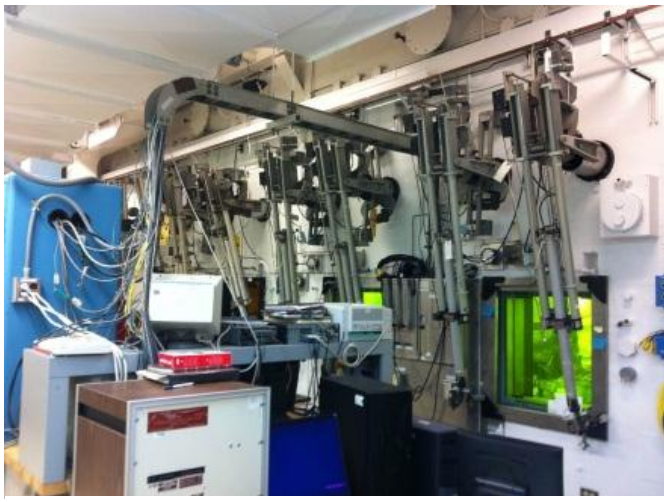

Test equipment control systems

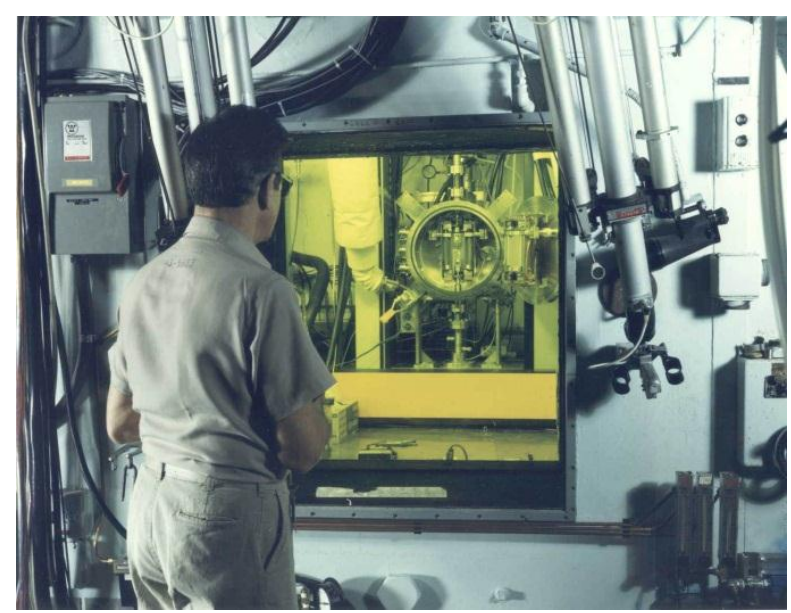

Mechanical load frame in Cell 2 


\section{Low Activation Materials Development and Analysis Laboratory}

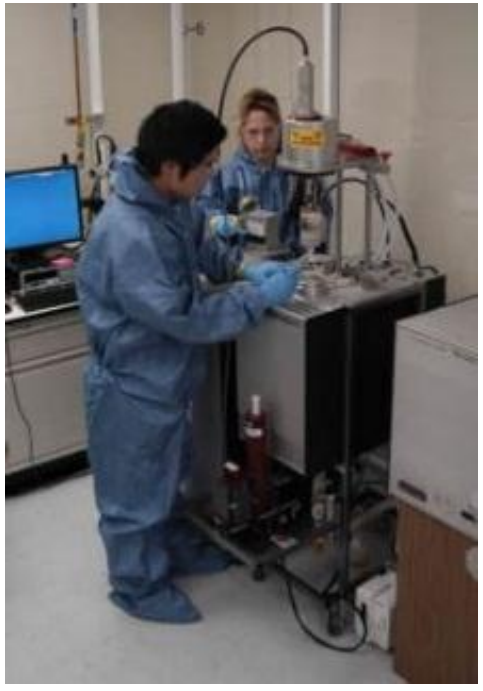

Specimen testing in LAMDA
The Low Activation Materials Development and Analysis Laboratory (LAMDA) facility is a world-class, multipurpose irradiated materials science facility for evaluation of materials with low radiological threat. It consists of four laboratory suites containing specialized instruments for materials testing and characterization. The LAMDA facility typically allows for the examination of low radioactivity samples $(<100 \mathrm{mR} / \mathrm{hr}$ at $30 \mathrm{~cm})$ without the need for remote manipulation. The preparation facilities for small and compact samples allow researchers to leverage cutting-edge characterization and testing equipment for studying radiation effects in materials. The most commonly conducted work includes mechanical testing, optical and electron microscopy, densitometry, metallography, thermal and electrical conductivity. New or infrequently performed activities are possible with appropriate planning.

The LAMDA facility is utilized by several programs within the Materials Science and Technology Division, with primary emphasis on the evaluation of irradiated materials. Current programs actively using the LAMDA facility include the US Department of Energy, the Naval Reactor Advanced Structural Materials Program, US Fusion Materials Sciences, US DOE-JAERI Fusion Materials Collaboration, US-Japan Jupiter-II Fusion Materials Collaboration, several NERI projects, the NE-Generation IV program, as well as international nuclear companies and research laboratories.

\section{Shared Research Equipment User Facility and the High Temperature Materials Laboratory}

The Shared Research Equipment (ShaRE) User Facility is one of three Electron Beam Microcharacterization Centers supported by the Scientific User Facilities Division of the Office of Science, U.S. Department of Energy. The Facility provides access to a suite of advanced instruments and staff scientists for the micrometer-to-angstrom-scale characterization of materials in electron microscopy and Atom Probe Tomography (APT). The High Temperature Materials Laboratory (HTML) is a national user facility designed to support the development of advanced materials. It is sponsored by the U.S. Department of Energy (DOE) Office of Transportation Technologies in the Office of Energy Efficiency and Renewable Energy. It houses six "user centers," which are clusters of specialized equipment designed for specific types of properties measurements.

The laboratories of ShaRE and HTML operate as "open use" areas, where radiation and contamination hazards are kept to minimal levels. While in use for the investigation of radioactive specimens, instruments and machines are temporarily labeled and the areas are temporarily zoned accordingly. Although activity limits for each instrument are different, all of those described here can be used for radioactive specimens. 


\section{MECHANICAL PROPERTIES TESTING}

\section{IMET (Irradiated Materials Examination and Testing Laboratory)}

- Tinius-Olsen Charpy Impact Machine:

instrumented; semi-automatic loading system; consistent control of test temperatures; rapid throughput; $360 \mathrm{~J}$ capacity; temperature range -196 to $250^{\circ} \mathrm{C}$; tests full size, $1 / 2$-size, and 1/3-size Charpy V-notch specimens; used primarily for fracture toughness testing and the determination of ductile-brittle transition temperature shifts.

- Instron Tensile Tester: screw driven; $100 \mathrm{kN}$ load frame; turbopump high vacuum chamber capable of pressures below $10^{-7}$ torr; furnace chamber will reach temperatures up to $1350^{\circ} \mathrm{C}$; variety of load cells and specimen grip systems

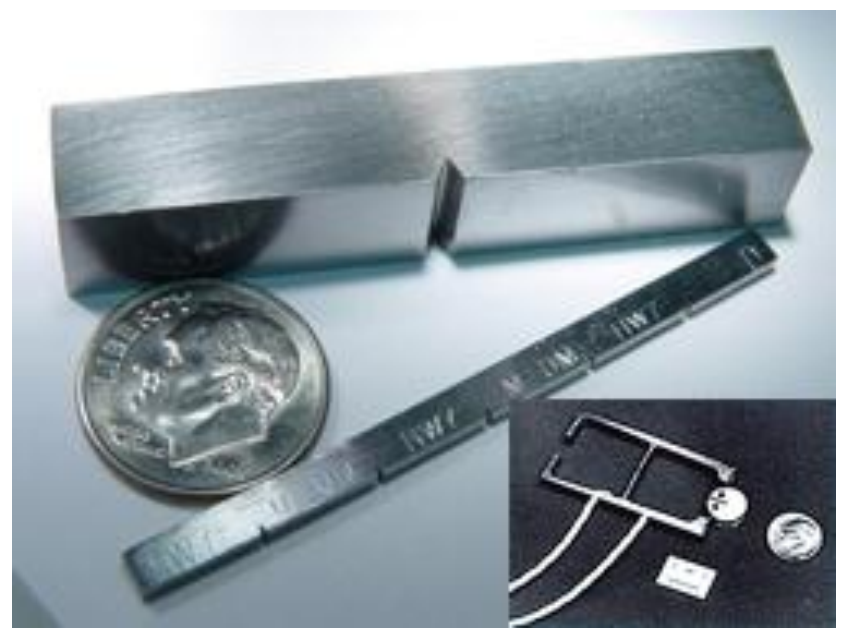

Several sizes of fracture toughness specimens for testing standard and miniaturized sheet and rod tensile specimens; used primarily for tensile strength measurements.

- Mitutoyo AAV-500 Automated Microindentation Hardness Tester: Vickers or Knoop indentations; automated user-defined indentation patterns; loads from 10 to $1000 \mathrm{~g}$; indentations automatically analyzed with a $0.3 \mathrm{~s}$ reading speed.

- MTS $450 \mathrm{kN}$ tension/compression servohydraulic universal testing machine: computer controlled; high vacuum furnace; temperatures up to $700^{\circ} \mathrm{C}$; pressures down to $1.5 \times 10^{-8}$ torr; strain and load control extensometry; used primarily for tension and compression strength testing.

- MTS Alliance 50/RT Test Frame: lead screw; $50 \mathrm{kN}$ load capacity; RF specimen heating; hydraulic grips; continuously variable speed control; load and strain measurement accuracy meets or exceeds ASTM E4.

- MTS Fatigue Testing Machine: can be used for fracture toughness, 3-point bend, large tensile, fatigue crack growth and crack arrest measurements; air environment; temperatures from -175 to $250^{\circ} \mathrm{C}$.

- Instron E300 Electro-servo Fatigue Test Machine: dynamic and static strength testing; high dynamic performance (> $100 \mathrm{~Hz}$ ); $\pm 3 \mathrm{kN}$ dynamic load capacity; $\pm 2.1 \mathrm{kN}$ long term static load capacity; $60 \mathrm{~mm}$ linear stroke; digital controller; high speed 2D measurement sensor.

- Deformation and Fracture Mechanics Bend (DFMB) Testing equipment: used to evaluate fracture toughness and post-irradiation fracture toughness transition temperature shifts. 

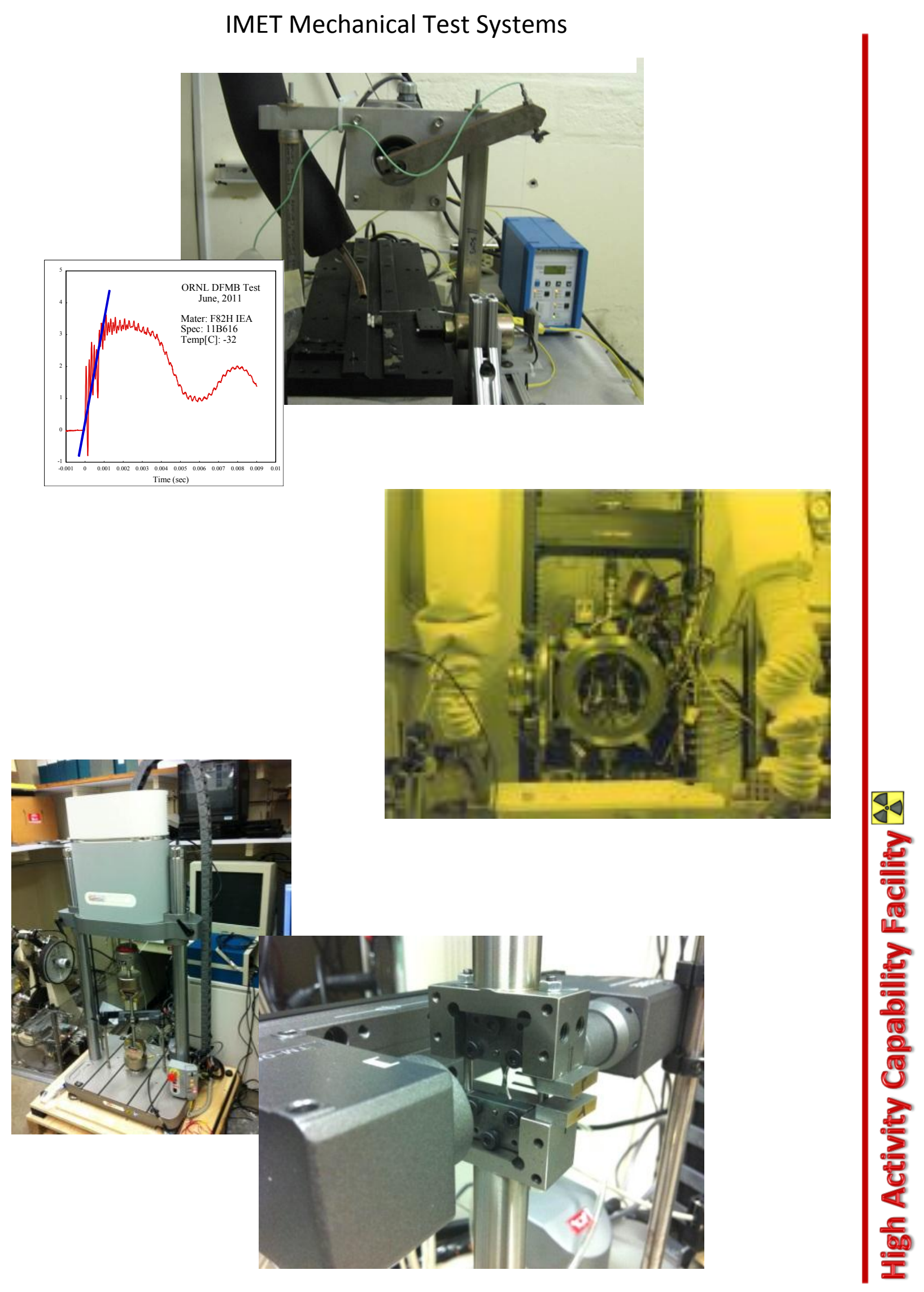


\section{LAMDA (Low Activation Materials Development and Analysis Laboratory)}

- MTS 858 Mechanical Test Frame: 10 kN load cell; testing in air at room temperature; clamshell furnace heating up to $1000^{\circ} \mathrm{C}$; vacuum down to $10^{-7}$ torr; Labview data acquisition; primarily used for flexural bend bar testing.

- MTS Insight 30 Mechanical Test Frame: $30 \mathrm{kN}$ load cell; ultra-fine-thread frame; testing in air; $\mathrm{RT}$ to $1800^{\circ} \mathrm{C}$; Labview data acquisition; laser extensometry available; used primarily for tensile strength evaluations.

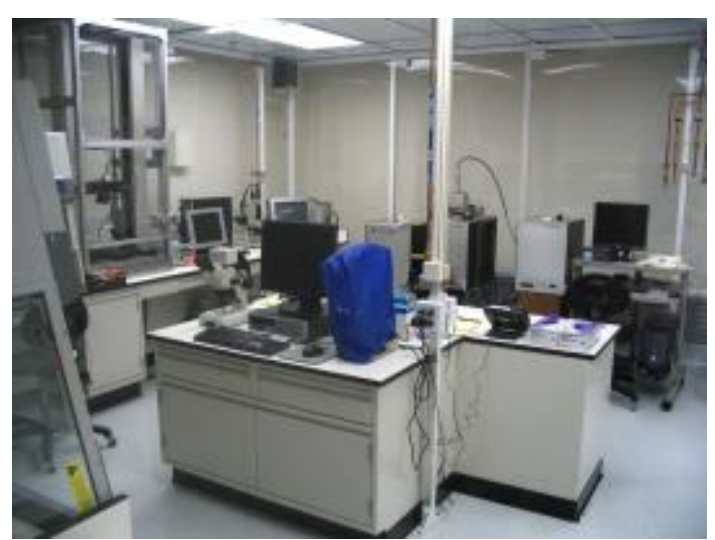

One of the LAMDA testing areas for contaminated specimens

- Instron 4301 Mechanical Test Frame: $125 \mathrm{~N}$ to $5 \mathrm{kN}$ load cells; in air or nitrogen cover gas; testing temperatures from -196 to $500^{\circ} \mathrm{C}$; used primarily for tensile strength evaluations.

- MTS Insight 10 Mechanical Test Frame: $1 \mathrm{kN}, 10 \mathrm{kN}$ load cells; tension, compression, flexural or torsional testing; inside decompressed enclosure; RT.

- MTS Mechanical Test Frame: $2 \mathrm{kN}$ load cell; tension or compression testing; RT.

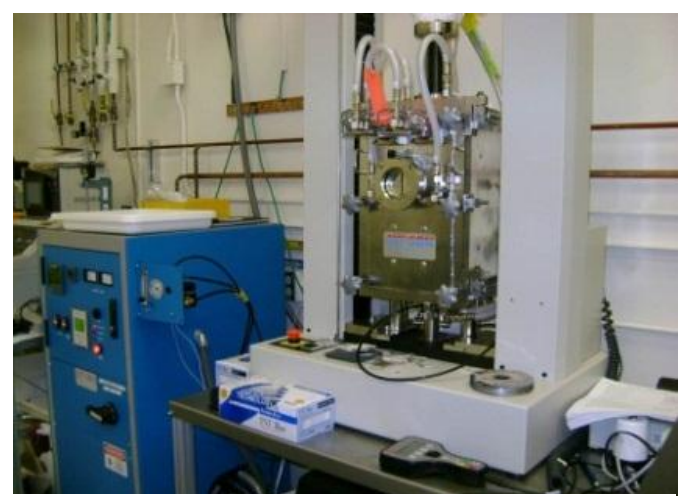

Mechanical test frame available in LAMDA

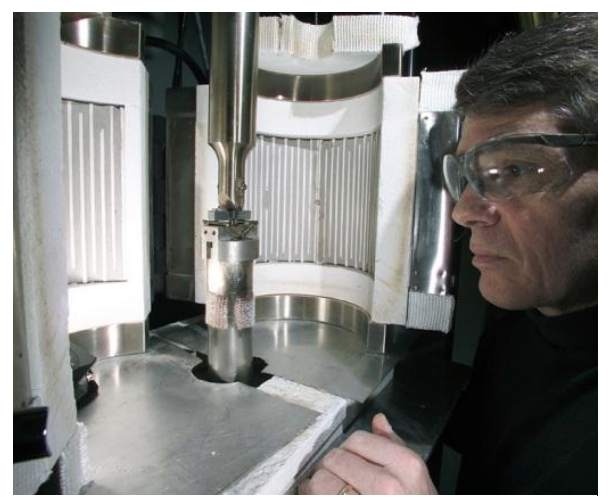

Fracture toughness testing of stainless steel cladding specimen
- $\quad$ Lloyd Mechanical Test Frame: $1 \mathrm{kN}, 10 \mathrm{kN}$ load cells; tension or compression testing; RT.

- Buehler Microhardness Tester: Vickers or Knoop indentations; 10 to $2500 \mathrm{~g}$ loads.

- Wilson Instruments Automated Microhardness Testers: Vickers or Knoop indentations; digital imaging; 10 to $1000 \mathrm{~g}$ loads.

- Mitutoyo Microhardness Testers: Vickers or Knoop indentations; 10 to $2500 \mathrm{~g}$ loads; automatic operation; programmable.

- JW Lemmens Grindosonic Instrument: nondestructive measurement of elastic properties for a wide range of materials using an impulse excitation of vibration technique; for determination of dynamic Young's modulus, shear modulus, and Poisson's ratio. 
- Sonic Velocity Measurement System: non-destructive measurement of elastic properties including Young's modulus, shear modulus, and Poisson's ratio based on the time of flight of sound waves through the material.

- Impact Testers: 25J capacity; Charpy and Izod test specimens; used for the evaluation of fracture toughness and ductile-brittle transition temperatures.

- Mini-Charpy Impact Testing Machines: 30J capacity; temperatures from -196 to $400^{\circ} \mathrm{C}$; used for the evaluation of fracture toughness and ductile-brittle transition temperatures.

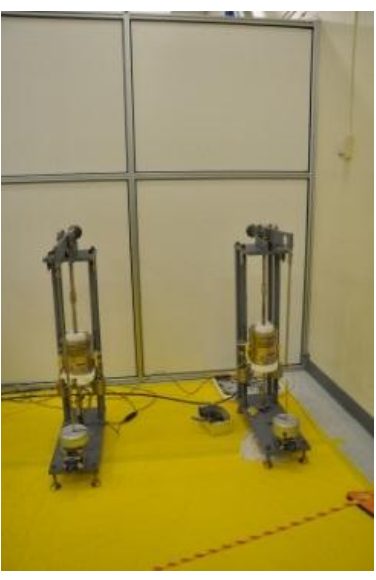

Creep test stands

- Creep Machines: $1 \mathrm{kN}$ load capacity; high resolution LVDT data acquisition; air; temperatures up to $500^{\circ} \mathrm{C}$; sample size gage section 5 to $25.4 \mathrm{~mm}$.

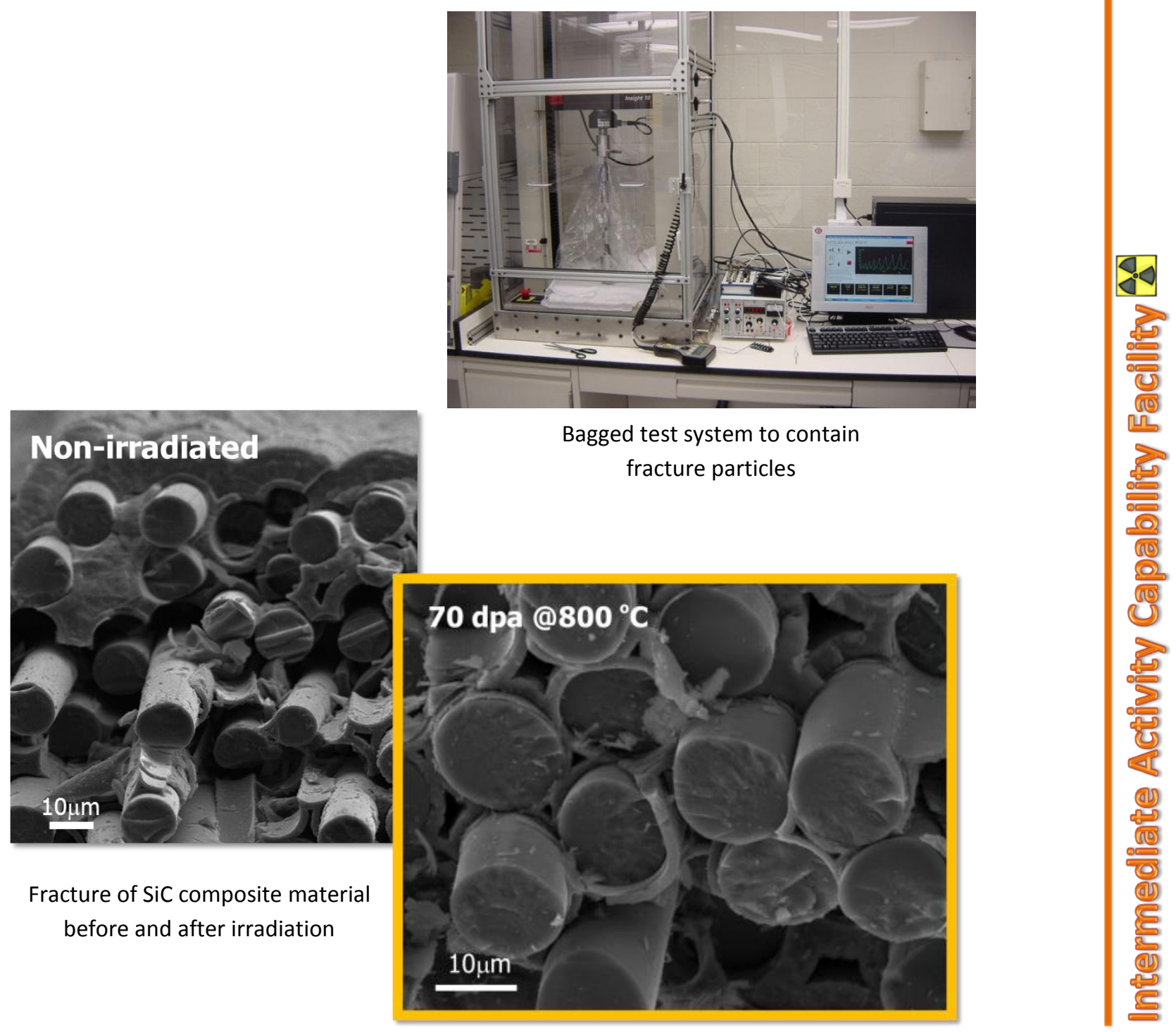




\section{PHYSICAL AND THERMOPHYSICAL PROPERTIES EVALUATION}

\section{IMET (Irradiated Materials Examination and Testing Laboratory)}

- BETA LaserMike Model 162

Scanning Optical Micrometer: inprocess, single-plane laser micrometer designed for highresolution, non-contact gauging; measurement range 0.127 to 25 $\mathrm{mm}$; linearity $\pm 0.0013 \mathrm{~mm}$; resolution $0.0002 \mathrm{~mm}$; repeatability $\pm 0.0002 \mathrm{~mm}$; used primarily for measuring radiationinduced creep in pressurized creep tube specimens.

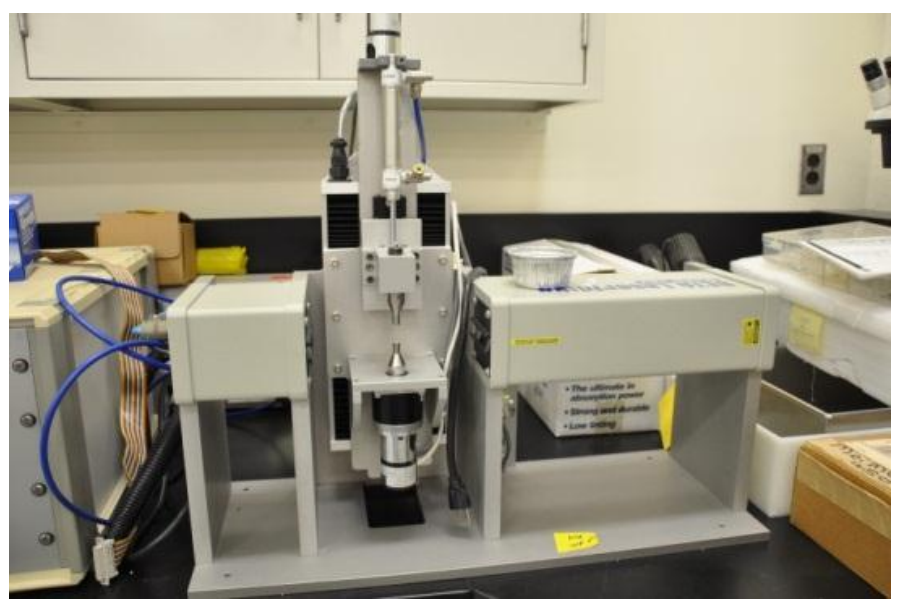

Optical micrometer available in IMET and LAMDA

\section{LAMDA (Low Activation Materials Development and Analysis Laboratory)}

- TA Instruments Q600 Simultaneous Differential Scanning Calorimeter (DSC) and Thermogravimetric Analysis (TGA) Unit: DSC measures specific heat capacity and heats of transition; detects phase changes and melting points; TGA examines time-temperatureenvironment relationships for materials in aggressive environments simulating processing or operating conditions; independent TGA measurements on two samples simultaneously; ambient to $1500^{\circ} \mathrm{C} ; 200 \mathrm{mg}$ sample size; $0.1 \mu \mathrm{g}$ balance sensitivity; $0.001^{\circ} \mathrm{C}$ DTA sensitivity; vacuum to 0.05 torr; reactive gas capability; true differential heat flow signal.

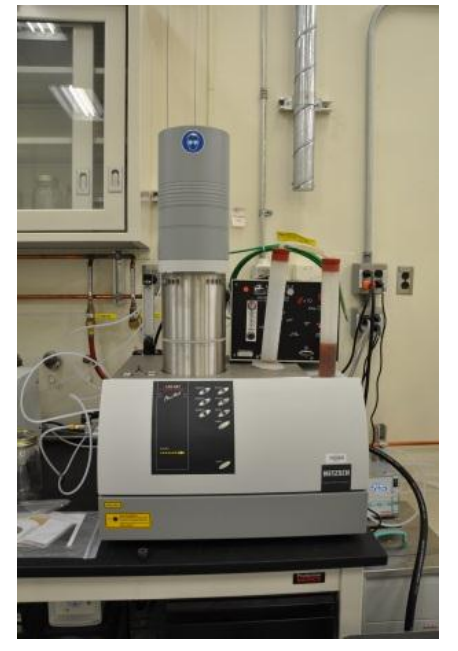

Xenon flash thermal diffusivity unit
- Netzsch DIL 402 CD Thermal Expansion Dilatometer: horizontal pushrod; vacuum-tight; RT to $1600^{\circ} \mathrm{C}$; dual specimen capacity; specimen size range up to $6 \mathrm{~mm}$ diameter x $30 \mathrm{~mm}$ long; rectangular cross sections can be accommodated; inert, oxidizing, reducing, static and dynamic atmospheres.

- Anter Dilatometer systems: ambient to $1000^{\circ} \mathrm{C}$.

- Anter Workhorse Continuous Thermal Expansion Dilatometer: $\mathrm{RT}-1000^{\circ} \mathrm{C}$.

- Anter Workhorse II Continuous Thermal Expansion Dilatometer: dual specimen capacity; RT $-1650^{\circ} \mathrm{C}$. 
- Netzsch LFA 447 NanoFlash Xenon Flash Thermal Diffusivity Apparatus: $\mathrm{RT}-300^{\circ} \mathrm{C}$; specimen size range $6-12.7 \mathrm{~mm}$ diameter disks or 6 × $6 \mathrm{~mm}$ squares; will accommodate up to 4 specimens at once; Xenon flash lamp up to $10 \mathrm{~J} /$ pulse; thermal diffusivity measurement range 0.01 to $1000 \mathrm{~mm}^{2} / \mathrm{s}$; thermal conductivity measurement range 0.1 to $2000 \mathrm{~W} / \mathrm{mK}$.

- Netzsch LFA 457 MicroFlash Laser Flash Thermal Diffusivity Apparatus; -125 to $1100^{\circ} \mathrm{C}$ range; specimen size

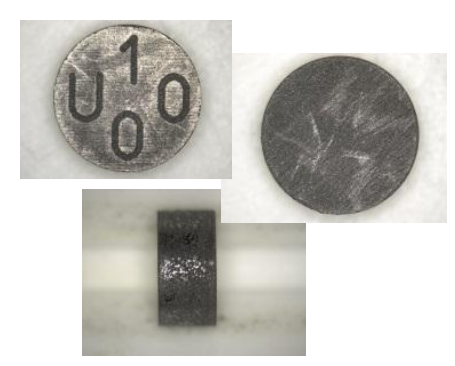

$6 \mathrm{~mm}$ thermal diffusivity specimens range $6,8,10$, and $12.7 \mathrm{~mm}$ diameter disks; will accommodate up to 3 specimens at once. Laser pulse energy up to $18 \mathrm{~J} /$ pulse; thermal diffusivity measurement range 0.01 to 1000 $\mathrm{mm}^{2} / \mathrm{s}$; thermal conductivity measurement range 0.1 to $2000 \mathrm{~W} / \mathrm{mK}$; vacuum tight; inert, oxidizing, reducing, static and dynamic atmospheres.

- Anter Flashline 3000 Thermal Diffusivity Unit: -150 to $200^{\circ} \mathrm{C}$ solid state unit; RT to $1000^{\circ} \mathrm{C}$ linear unit; specimen diameters from 5.8 to $12.7 \mathrm{~mm}$; thermal diffusivity and specific heat capacity measurement; thermal conductivity derived; tests up to 3 samples simultaneously; meets ASTM E1461.

- Anter Flash thermal diffusivity systems: one to six sample stage, 6 to $37 \mathrm{~mm}$ diameter; liquid nitrogen to $1600^{\circ} \mathrm{C}$ with solid state and infrared detector; measures thermal diffusivity from which thermal conductivity can be derived.

- BETA LaserMike Model 162 Scanning Optical Micrometer: in-process, single-plane laser micrometer designed for high-resolution, non-contact gauging; measurement range 0.127 to $25 \mathrm{~mm}$; linearity $\pm 0.0013 \mathrm{~mm}$; resolution $0.0002 \mathrm{~mm}$; repeatability $\pm 0.0002 \mathrm{~mm}$; used primarily for measuring radiation-induced creep in pressurized creep tube specimens.

- Density gradient columns: density measurements up to $3.2 \mathrm{~g} / \mathrm{cc}$; accuracy to $1 \mathrm{mg} / \mathrm{cc}$.

- Sartorious Genius Analytical Microbalance ME235S: 230 g capacity; $0.01 \mathrm{mg}$ readability.

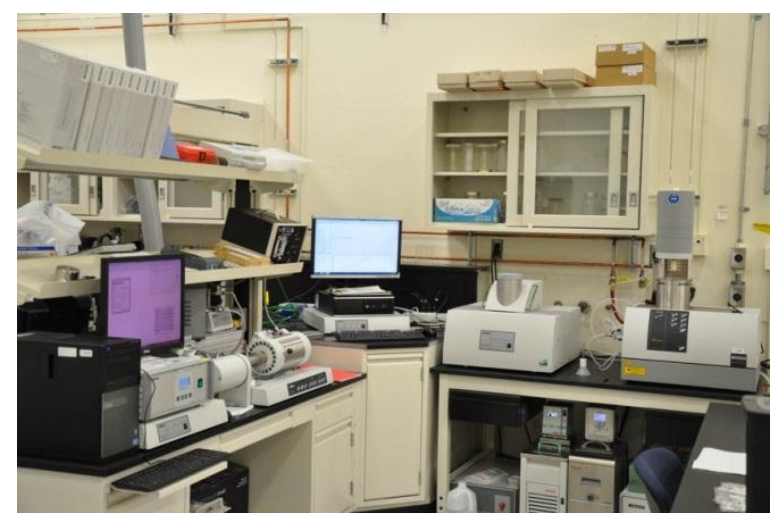

- $\quad$ Calipers and micrometers: $0.001 \mathrm{~mm}$ resolution; automatic digital input via USB.

- $\quad$ Keithley Electrical Resistivity Meter: four probe devises for different sample geometries; RT and boiling liquid nitrogen temperatures.

Thermal expansion dilatometer and thermal diffusivity units available in LAMDA 


\section{ShaRE/HTML (Shared Research Equipment User Facility and the High Temperature} Materials Laboratory)

- Multipurpose X-Ray Powder Diffraction: provides either divergent or parallel-beam optics coupled with high temperature stages; Anton Paar XRK 900 high-temperature furnace with rotating sample stage (RT to $900^{\circ} \mathrm{C}$ ); Anton Paar HTK16 HT furnace Pt strip heater (RT to $1600^{\circ} \mathrm{C}$ ); Multipurpose RT sample stage; X'Pert Plus Crystallography and Rietveld software; applications include phase equilibria studies, thermal expansion using parallel beam or divergent optics, HT residual stress using parallel beam optics and HT phase transformations.

- Room Temperature X-Ray Powder Diffractometer: PAN analytical X'Pert Pro MPD vertical goniometer; Cu X-ray target; programmable slits; X'Celerator RTMS detector with optional monochromator; single or 15 position sample holder.

- Multiple-Station Laser Flash Thermal Diffusivity System: cryogenic temperatures to $2500^{\circ} \mathrm{C}$; bulk and layer sample measurements; vacuum, inert, oxidizing, or reducing atmospheres; six samples per run measurement capability; thermal contact resistance between two layers; finite pulse-width and heat-loss corrections.

- Xenon Flash Thermal Diffusivity System: optimized for rapid room-temperature thermal diffusivity measurements; measures bulk and layer samples; accepts a wide range of specimen sizes and shapes.

- Hot Disk Thermal Conductivity System: hot disk sensor sandwiched between two pieces of sample; sensor is used both as heat source and as a dynamic temperature sensor.

- Anter Flashline 5000 Laser Flash Thermal Diffusivity Instrument: measures thermal transport properties over a wide range of temperatures; laser pulse source with safety interlocks; operating ranges from $-180^{\circ} \mathrm{C}$ to $200^{\circ} \mathrm{C}$, and RT to $1600 / 2000 / 2500 / 2800^{\circ} \mathrm{C}$; exclusive full-range optical pyrometer; round and square shaped samples; specific heat capacity determination; thermal conductivity measurements in metals, ceramics, carbons, graphite, and polymers; meets ASTM E1461.

- TA Instruments Q5000IR Thermogravimetric Analyzer: ultra-sensitive thermobalance $(<0.1$ $\mu \mathrm{g}$ ); weight range $0.1 \mathrm{~g}$; infrared furnace controls ambient to $1200^{\circ} \mathrm{C}$; linear and ballistic heating rates; multi-position sample carousel holds up to 25 samples; precise purge gas flow rates; vacuum down to $10^{-2}$ torr. 
- Fourier Transform Infrared Spectroscopy (FTIR) system: Thermo Nicolet Nexus 670 Optical Spectrometer; range of 7,400-350 $\mathrm{cm}^{-1}$ and a spectral resolution of $0.125 \mathrm{~cm}^{-1}$ for use with attached cells: Diamond ATR, DRIFTS and transmission.

- FLIR Infrared Cameras: high performance generation of thermal diffusivity maps of bulk materials, especially composites; temperature mapping; non-destructive evaluation; process monitoring, high speed imaging and machine-vision applications; Near-IR $(0.9-1.7 \mu \mathrm{m})$, Mid-IR $(1.5-5 \mu \mathrm{m})$, and Long IR $(7-14 \mu \mathrm{m})$ cameras; cameras are portable and may be used for low and high level radioactive materials.

- Seebeck Coefficient and Electrical Resistivity System: Seebeck coefficient (thermopower) of bulk and thin films; electrical resistivity of bulk and thin films; room temperature to $800^{\circ} \mathrm{C}$; for bulk specimens, typical samples are $3 \mathrm{~mm} \times 3 \mathrm{~mm} \times 15 \mathrm{~mm}$; thin film samples should be on insulating substrates, and the substrate needs to be at least $1 \mathrm{~mm}$ thick and 3 mm wide.

- Solartron Impedance Spectroscopy System: includes dielectric impedance interface for highly resistive samples.

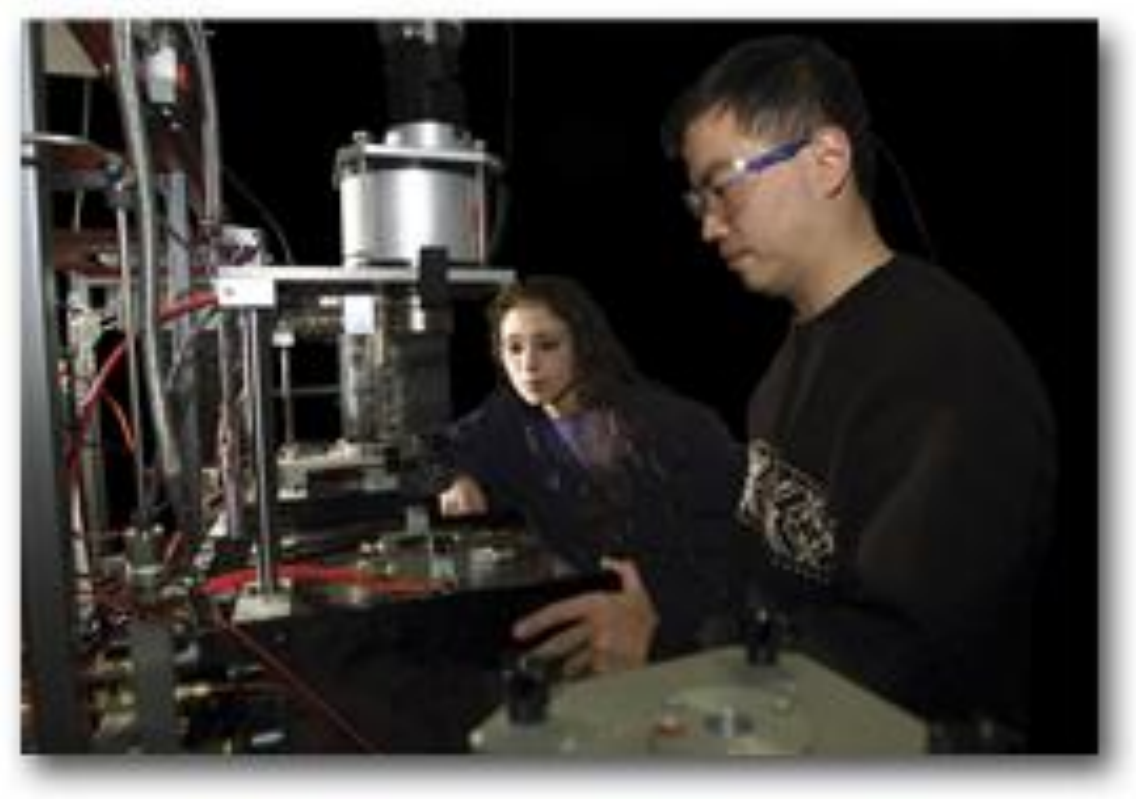

A wide variety of physical and thermal properties are investigated within the open use areas of the HTML 


\section{MICROSTRUCTURAL CHARACTERIZATION}

\section{IMET (Irradiated Materials Examination and Testing Laboratory)}

- FEI Philips XL30 Scanning Electron Microscope: LaB6 or W filaments; computer-controlled operation; internetinterface data transfer.

- Low power digital microscope:

$7-40 \times$ with

measurement capability.
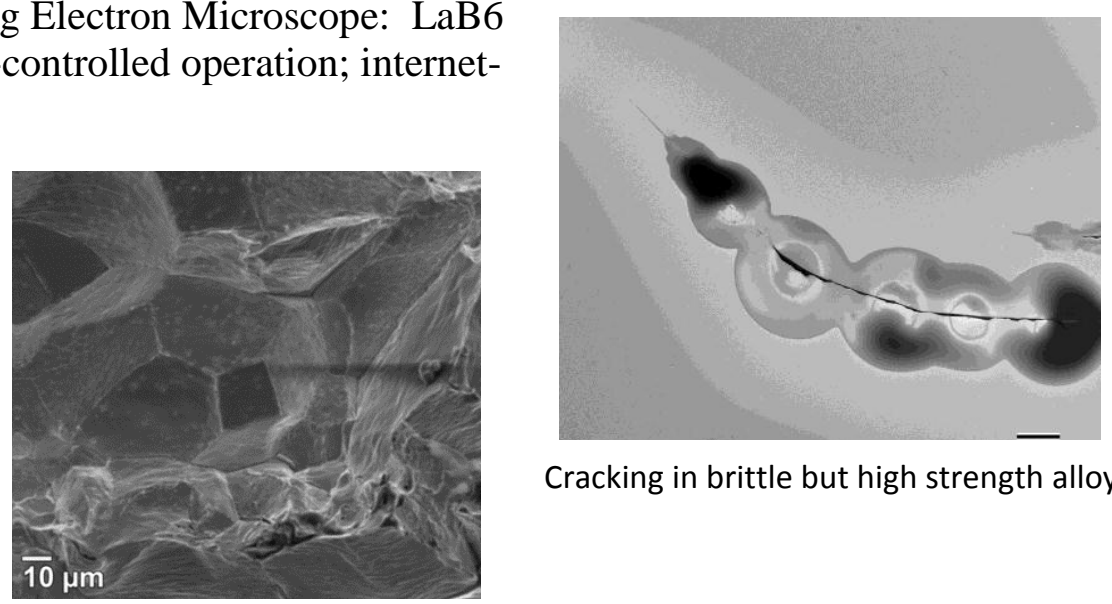

Cracking in brittle but high strength alloy

Examination of fracture surface by SEM

\section{LAMDA (Low Activation Materials Development and Analysis Laboratory)}

- Hitachi S-4700 Field Emission Scanning Electron Microscope: SE and BSE imaging; capable of $1.5 \mathrm{~nm}$ resolution at $15 \mathrm{kV}, 12 \mathrm{~mm}$ W.D.; and $2.5 \mathrm{~nm}$ resolution at $1 \mathrm{kV}, 2.5 \mathrm{~mm}$ W.D.; magnification ranges from $30 \mathrm{X}$ to $500,000 \mathrm{X}$; specimen tilt at $12 \mathrm{~mm}$ W.D. up to 45 degrees. Electron source is a cold FE gun producing high brightness $\left(\sim 2 \mathrm{X} 10^{9} \mathrm{~A} / \mathrm{cm}^{2} / \mathrm{sr}\right)$ with little energy spread $(0.2-0.3 \mathrm{eV})$; accommodates samples as large as $100 \mathrm{~mm}$ diameter $\mathrm{x} 17 \mathrm{~mm}$ thick.

- Top Con 510 Scanning Electron Microscope: Princeton Gamma Tech imaging and EDS; insitu straining fixture; backscatter imaging.

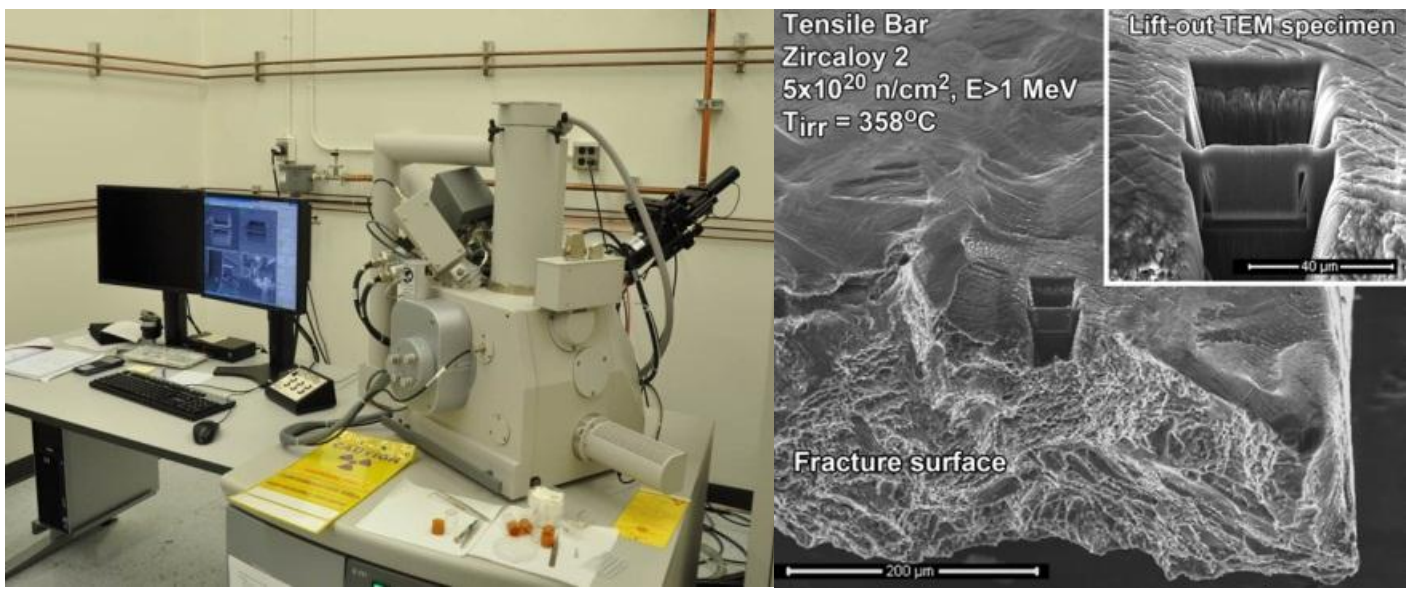

FIB machining of near-fracture surface 
- FEI Dual Beam Focus Ion Beam Quanta 3D 200i OmniProbe: scanning transmission electron microscope, backscatter, and specimen lift-out capabilities; combines scanning electron microscope (SEM) with a high current focused ion beam (FIB) milling unit; can be used for characterizing and modifying materials; current-boosted tungsten SEM for submicron structure imaging; high current ion column can be used to precisely prepare samples by removing or depositing material at a rapid rate in small defined areas; 3D nanoanalysis, TEM, EBSD and atom probe sample preparation, or structural modification of sample surfaces at the nanometer scale; $200 \mathrm{~V}$ to $30 \mathrm{kV}$ electron optics with $<4 \mathrm{~nm}$ resolution at 30 $\mathrm{kV} ; 2$ to $30 \mathrm{kV}$ ion optics with $9 \mathrm{~nm}$ resolution at $30 \mathrm{kV}$; variable pressure

$\checkmark$ one unit located inside a lead-lined vault with remote console and can be used for high activity samples

$\checkmark$ second unit also available and can be used with alpha-containing samples.

- Hitachi HD 2000 Scanning Transmission Electron Microscope (STEM): 200 kV FEG; high sensitivity elemental microanalysis through EDS; secondary, transmitted, and scattered electron detectors; Z-contrast imaging.

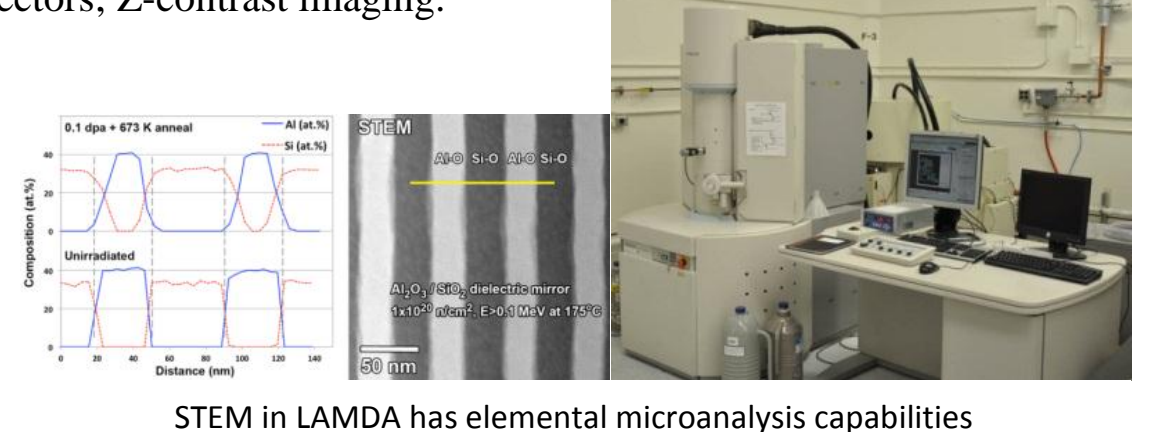

- Keyence Digital Optical Microscope: high resolution; 5-50X, 100-500X, and 500-5000X interchangeable lenses; measuring and 3D tools; real-time image stitching; high depth of field; precision stage; polarizer filter.
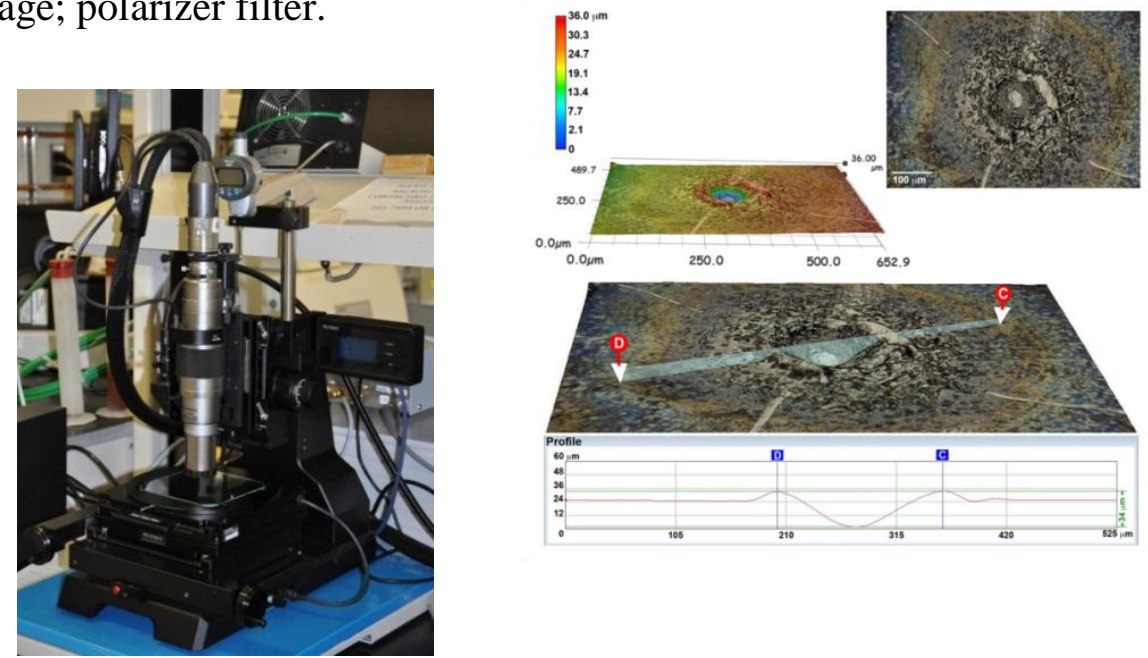

Measuring and 3D tools are available using digital microscope 


\section{ShaRE/HTML (Shared Research Equipment User Facility and the High Temperature} Materials Laboratory)

- Phillips CM200 Transmission Electron Microscope/Scanning Transmission Electron Microscope (TEM/STEM): 200 kV Schottky field-emission gun (FEG); post-column Gatan imaging filter (GIF) for EFTEM and EELS; EDAX R-TEM Si(Li) X-ray spectrometer; Fischione HAADF (Z-contrast) and Gatan BF/DF STEM detectors; CompuStage SuperTwin lens ( $\pm 30^{\circ}$ tilt); Gatan Digiscan acquisition system for integrated STEM, EFTEM, EDS, and EELS; double-tilt low background EDS (RT and $\mathrm{LN}_{2}$ cooling) specimen holders; wide range of pre-CompuStage holders for in-situ mechanical testing.

- FEI Tecnai-20 Transmission Electron Microscope (TEM): 200 kV LaB 6 filament; generalpurpose transmission electron microscope.

- Hitachi HF3300 Transmission Electron Microscope/Scanning Transmission Electron Microscope/Scanning Electron Microscope (TEM/STEM/SEM): $100 \mathrm{kV}$ and $300 \mathrm{kV}$ operation; cold FEG; Bruker SDD-EDS and spectrum imaging; Gatan Quantum 953 EELS/GIF; dual, bi-prism assembly for electron holography; SEM, BF-STEM, and HAADFSTEM detectors; high-resolution TEM imaging $(\sim 0.12 \mathrm{~nm})$; remote access; heating holder (Protochips - $1000^{\circ} \mathrm{C}$ ); Gatan CT3500 Cryo-transfer holder; Hitachi $360^{\circ}$ Rotation MicroPillar tomography holder; Hummingbird Scientific Liquid Flow Holder.

- FEI Titan S 80-300 Transmission Electron Microscope/Scanning Transmission Electron Microscope (TEM/STEM): CEOS probe-corrector and EELS/GIF; Extreme Schottky-field emission gun (X-FEG); CEOS dodecapole probe (STEM) aberration corrector; GIF Quantum with dual EELS and fast spectrum imaging capabilities; operating voltages of $60 \mathrm{kV}, 120 \mathrm{kV}$, and $300 \mathrm{kV}$; HAADF/ADF/BF STEM detectors; advanced version 2k X 2k UltraScan CCD; CompuStage SuperTwin lens $\left( \pm 30^{\circ}\right.$ tilt); dedicated holders include FEI single/double tilting holders, vacuum transfer holder, Nanofactory AFM/STM holders and $\mathrm{LN}_{2}$ cooling holder.

- Nion UltraSTEM 60-100 Scanning Transmission Electron Microscope: dedicated aberration-corrected STEM for low- to mid-voltage operation and Enfina EELS; cold field emission gun; 3rd generation C3/C5 aberration corrector; $60-100 \mathrm{kV}$ operation; $<1 \AA$ spatial resolution at $100 \mathrm{kV} ;<1.1 \AA$ spatial resolution at $60 \mathrm{kV}$; $>0.5 \mathrm{nA}$ of current with atom-sized probe; $<350 \mathrm{meV}$ energy resolution at $100 \mathrm{kV}$; Gatan Enfina EELS; ultrastable sample stage; up to 5 samples can be loaded/exchanged with no vacuum degradation; flexible electron optics (diffraction and CTEM modes); atomic resolution imaging and spectroscopy at mid- and lowvoltage with single atom sensitivity.

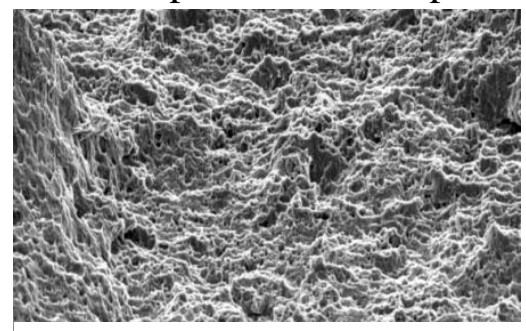

Fracture surface of ODS 14YWT tensile specimen 
- JEOL 6500 Scanning Electron Microscope (FEGSEM/OIM) : high current, $30 \mathrm{kV}$ gun; secondary and backscattered electron imaging; low voltage imaging; Si drift detector for X-ray microanalysis ( $\mathrm{Z}>3)$; Fast EDS spectrum imaging; high speed EBSD/OIM camera; dry pumping system/in-situ plasma cleaning of specimens.

- Thermo Scientific K-Alpha X-Ray Photoelectron Spectroscopy (XPS): XPS provides elemental and

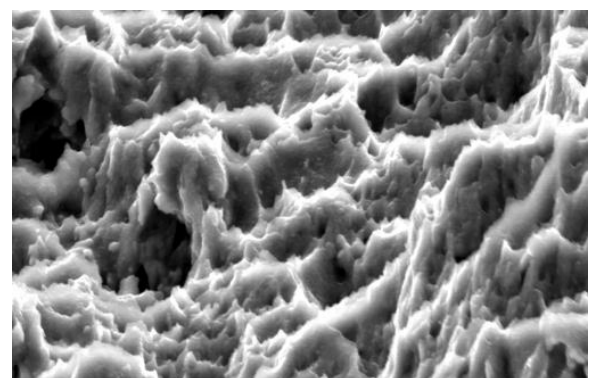

Fracture surface of ODS 14YWT tensile specimen chemical information at moderate spatial resolution (30-400 microns); focused monochromatic Al x-ray source and high performance hemispherical electron energy analyzer; integrated Ar-ion sputter gun allows depth profiling; charge compensation during analysis allows for analysis of all solid materials, including insulators; provides materials analysis of the very upper surface of solid materials (top 2-3 nm); often used as a complement to the scanning Auger system.

- Phi 680 Scanning Auger Nanoprobe: field-emission electron gun and a cylindrical mirror electron analyzer; Ar-ion sputter capabilities are also available for depth profiling through thin films; provides materials analysis of the very upper surface of solid materials (top 2-3 $\mathrm{nm}$ ); scanning Auger provides only elemental information but at very high spatial resolution (below $20 \mathrm{~nm}$ ); often used as a complement to the XPS system.

- Dilor XY800 Raman Microprobe System: spatial resolution about $2 \mu \mathrm{m}$; depth resolution about $5 \mu \mathrm{m}$; cooling/heating stage with a range from -196 to $1500^{\circ} \mathrm{C}$; $2 \mathrm{D}$ mapping; macro stage for large samples.

- Keyence digital microscope and optical profiler for height and roughness measurements.
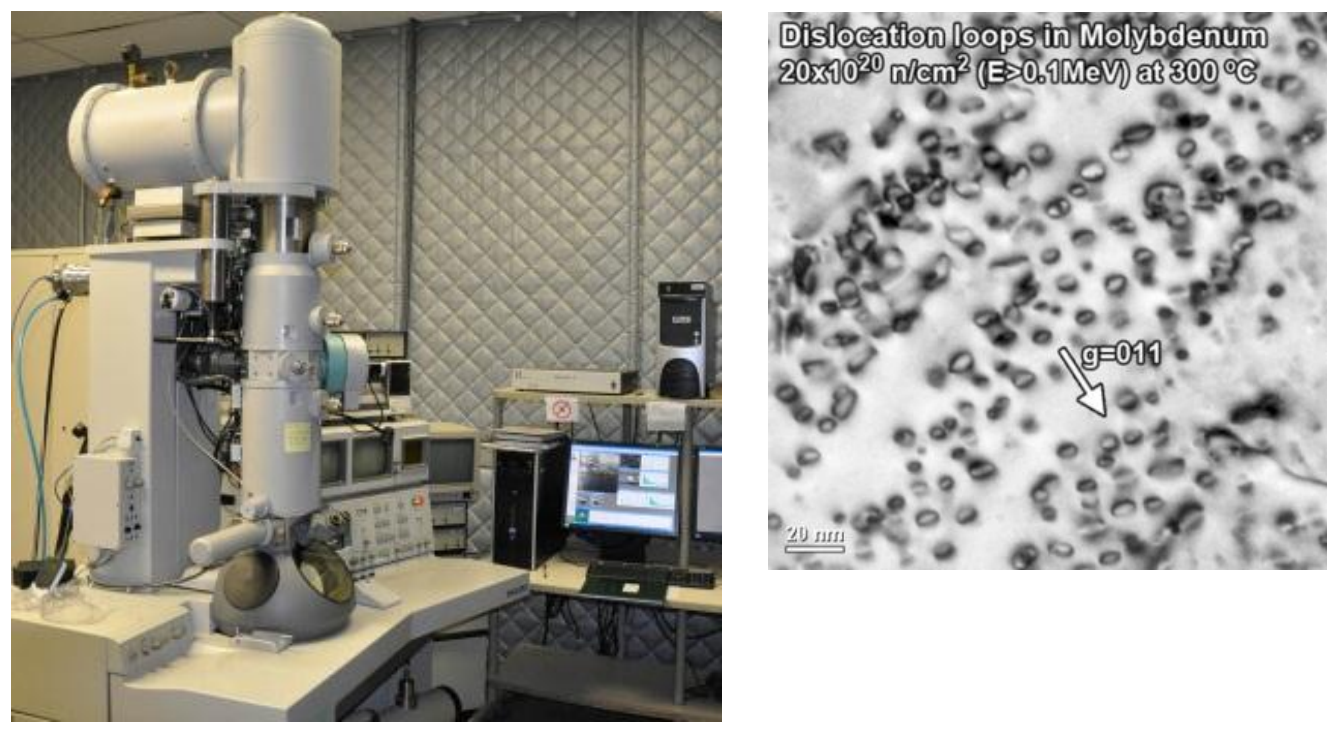

Transmission electron microscopy imaging of dislocation loops in Molybdenum 


\title{
SPECIMEN PREPARATION EQUIPMENT
}

\author{
IMET (Irradiated Materials Examination and Testing Laboratory)
}

- Annealing Furnace: air; temperatures up to $1000^{\circ} \mathrm{C}$.

- Lathe available on campaign basis.

- Radioactive specimen preparation area: located adjacent to the hot cells; consists of three shielded glove boxes and a chemical hood with HEPA ventilation; connections to the ORNL low-level liquid waste system; can be used for preparation of transmission electron microscopy specimens and other specialized activities.

\section{LAMDA (Low Activation Materials Development and Analysis Laboratory)}

- FEI Dual Beam Focus Ion Beam Quanta 3D 200i OmniProbe high current milling unit with specimen lift-out capabilities; prepare specimens by removing or depositing material in small areas (2)

- FISCHIONE model 1010 ion miller: non-conductive and cross-section TEM specimen preparation; liquid nitrogen cooled specimen stage; 0 to $45^{\circ}$ milling angle, 0.5 to $6 \mathrm{kV}$ extractor voltage.

- Gentle Mill Ion Mill: 100 - 2000 V low angle milling, post FIB sample cleaning.

- Struers TenuPol: jet polisher for TEM specimen preparation via electrolytic polishing.

- Struers Lectropol 5 Electropolishing unit

- Coil wire electropolishing unit

- Buehler Mini Met mechanical polisher

- Buehler EcoMet 250 Mechanical Polisher

- Buehler Isomet low speed saws

- Buehler Isomet 1000 low speed saw.

- MRF High vacuum furnace: pressures down to $10^{-7}$ torr; temperatures up to $1800^{\circ} \mathrm{C}$.

- Vacuum furnace. capable of $2000^{\circ} \mathrm{C}$ in vacuum of $10^{-6}$ torr.

- Various box furnaces: temperatures up to $1300^{\circ} \mathrm{C}$ in air.

ShaRE/HTML (Shared Research Equipment User Facility and the High Temperature Materials Laboratory)

- Gatan Precision Ion Polishing System

- Fischione Model 1010 Ion Mill

- Fischione Model 1040 Nanomill

- Fischione Model 1020 Plasma Cleaner

- Gatan Dimple Grinders

- Allied Techprep Grinder/Polisher

- Buehler Isomet Low Speed Saws

- Struers TenuPol-5 Electropolisher (2)

- Tri-pod and cross-section TEM preparation

- Leica Ultracut UCT (Ultra, Histology knives)

- Leica EM FCS (Cryo-Ultramicrotomy System)

- Leica EM Trim

- EMS-002 Plunge Freezer

- Gatan CT-3500 Cryo Transfer Holder/System

- Gatan Dry Pumping Station

- Cressington Sputter Coater - Ir, Pd, Pt targets

- Cressington Carbon Coater

- Bio-Rad Sputter Coater - Pt/Pd, Au targets

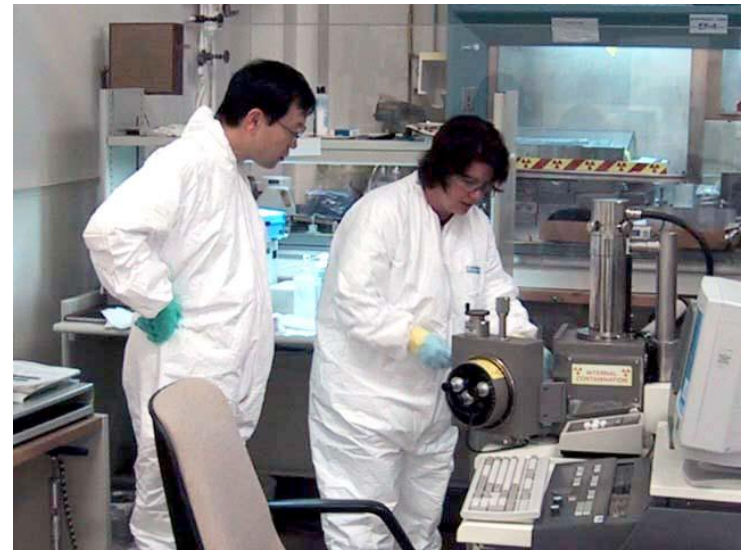

Preparation and examination of radioactive specimens in LAMDA 


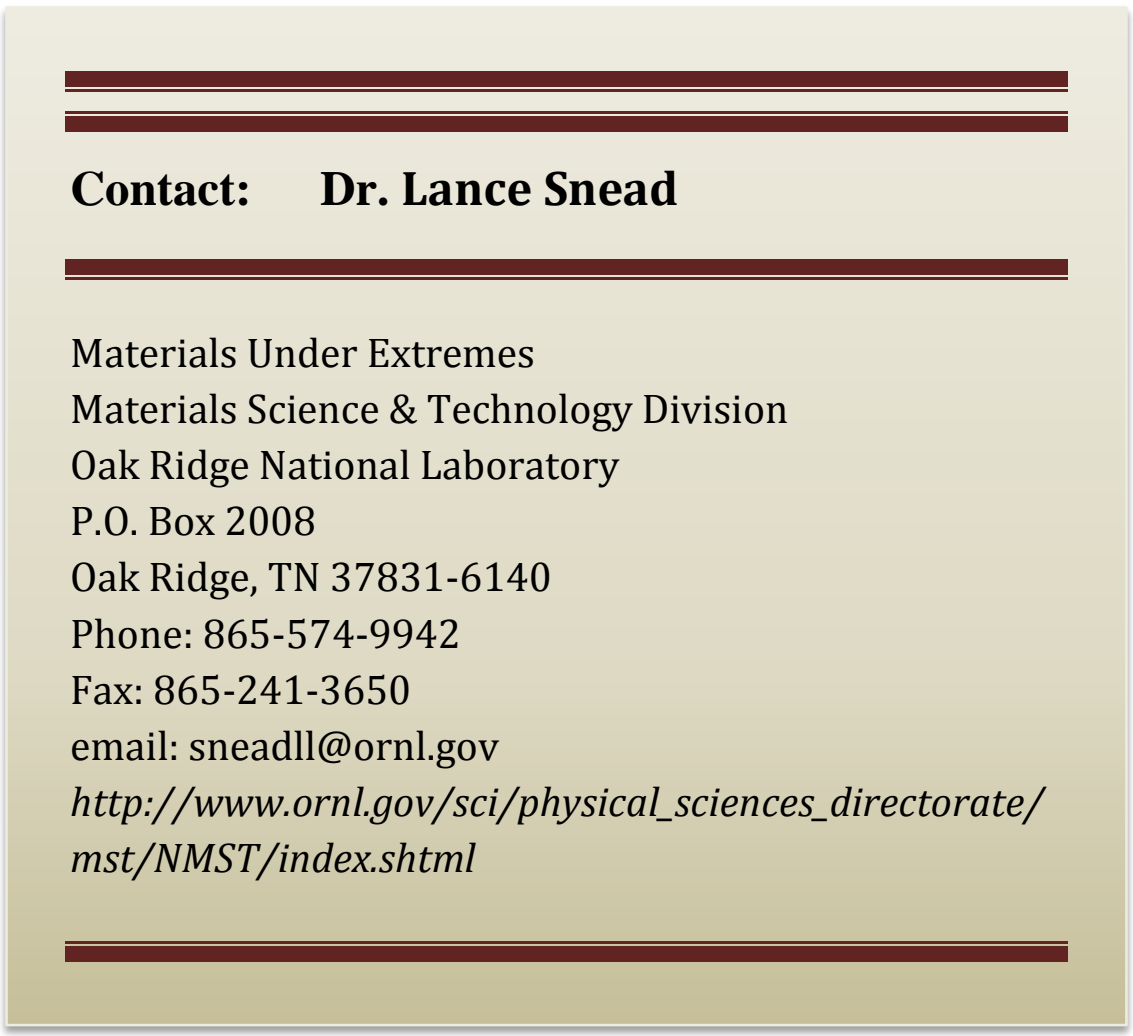

